\title{
RISK IDENTIFICATION AND ASSESSMENT IN PRODUCTION OF MEAT PRODUCT PACKAGING
}

\author{
Yulya A. Kuzlyakina ${ }^{1 \star}$, Valentina S. Zamula ${ }^{1}$, Margarita V. Kochneva ${ }^{2}$ \\ ${ }^{1}$ V.M. Gorbatov Federal Research Center for Food Systems of Russian Academy of Sciences, Moscow, Russia \\ ${ }^{2}$ Peoples ' friendship University of Russia, Moscow, Russia
}

\begin{abstract}
Keywords: meat packaging, polypropylene packaging, packaging materials, risk assessment, safety system
Abstract

Production of convenient and inexpensive packaging materials is increasing due to the constant growth of consumer demand for safer food products. The paper examines the questions dedicated to the development and introduction of the safety and quality management system in enterprises producing packaging for the meat industry. The authors analyze the elements of safety and quality management for polypropylene packaging in a form of a tray, which is a final element of the united chain in production of whole-piece meat semi-finished products. The investigations were carried out in the operating enterprise in the Moscow region. Hazardous factors in production of polypropylene packaging were identified, risk analysis with assessment of the probability of emergence and realization of hazardous factors was carried out, a Pareto chart was built, unacceptable risks were determined, critical control points (CCP) were revealed, preventive and corrective measures were developed with account for the established critical limits and requirements for CCP monitoring were formulated. All stages of production process were subjected to risk analysis; the severity of consequences from hazardous factor realization and the probability of such realization were assessed by experts for each of these stages. It was established that "injection molding and chilling in a press-mold" is a CCT as there is a risk of increasing the maximum allowable concentrations of chemical substances and compounds (formaldehyde, ethyl acetate, alcohols and others) as a chemical factor with the severity of consequences of 3 and the probability of realization of 3 . Using the Pareto chart, causes that had the highest effects on safety and quality of polypropylene packaging were grouped. It was established that nonobservance of preventive maintenance schedule for equipment and, as a consequence, possible equipment failure (80\%) influenced to the higher degree the realization of chemical hazardous factor.
\end{abstract}

\section{Introduction}

In the modern world, high requirements are imposed to quality and safety of food products. Food enterprises that strive to be competitive and want to keep their place in the market should take into account risks associated with product safety assurance. This explains the active development and worldwide introduction of such management systems that would guarantee stable quality and safety of manufactured products for consumers [1,2].

Nowadays, enterprises use many certification standards and schemes according to the requirements of food safety and quality management systems; however, a basic model is the HACCP system (Hazard Analysis and Critical Control Points) $[2,3,4]$.

HACCP is an instrument used to assess hazards and risks, and establish specific control measures that emphasize prevention, rather than final product testing. An increase in public awareness about food safety has led to the fact that manufacturers began to demand higher standards from their suppliers. Suppliers of raw materials, ingredients and food packaging should bring their hygiene standards in correspondence with expectations of the meat industry. Food manufacturers should be guaranteed that packaging has no negative effects on their products. HACCP is a method that can be used for safety assurance [5].
Based on the research carried out in 100 companies in the packaging sector in Poland [6], it was confirmed that hazard analysis and critical control points (HACCP) are the most effective management instrument for ensuring safety of manufactured products (50\%). Moreover, enterprises develop, introduce, maintain and actualize programs of prerequisite measures based on Good Manufacturing Practice (GMP-74\%) and Good Hygiene Practice (GHP). They include sanitation, zonation of territories according to a type of production process, storage, distribution and transportation, personal hygiene of employees, deratization and disinsection, water supply, illumination and ventilation, proper wastewater disposal, proper work of equipment; that is, they ensure the main conditions and measures necessary to maintain the basic level of sanitary and hygiene in an enterprise. Only $8 \%$ of the surveyed manufacturers introduced BRC. The fact that $10 \%$ of manufactures and even $45 \%$ distributers have not introduced any system (Figure 1) is also of concern [6].

Introduction of safety and quality management systems give enterprises several advantages:

- system approach to safety assurance for manufactured products;

- increase in consumer confidence in manufactured products;

- possibility to enter new markets; 
- savings due to an increase in efficiency and improvement in labor performance;

- additional advantages when taking part in important tenders;

- optimization of management processes;

- distribution of authority, responsibility and communication of personnel;

- use of preventive measures rather than late actions on correction of defects and product recall;

- identification of food risks and introduction of the necessary work order;

- reduction of the number of claims due to assurance of stable product quality;

- increase in competitiveness of an enterprise;

- creation of the reputation as a manufacturer of safe and quality products;

- significant decrease in the level of non-compliant products due to the use of preventive and corrective measures;

- documentation of safety of manufactured products $[7,8,9]$.

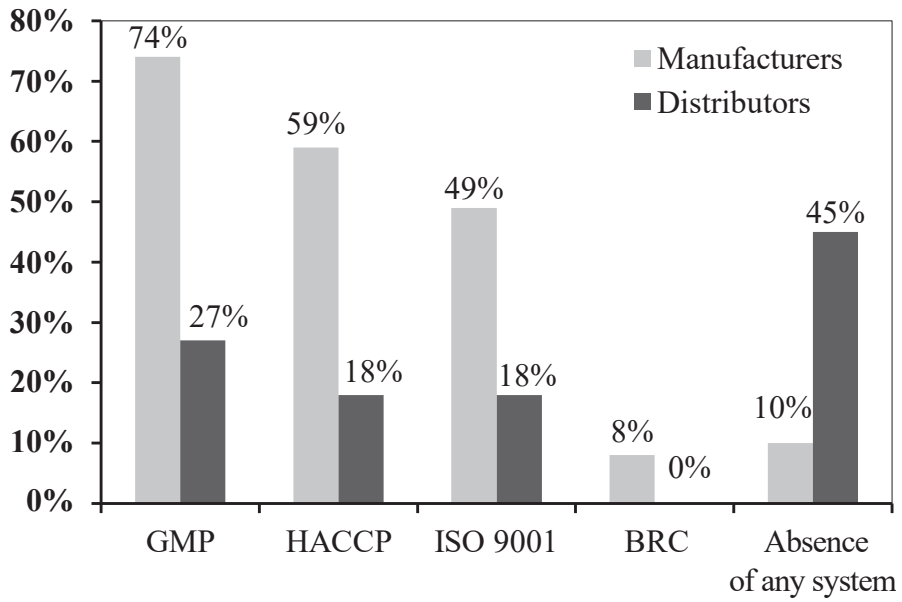

Figure 1. Introduction of safety and quality management systems in the packaging industry in Poland [6]

The role of packaging in the meat industry is quite high. First of all, it is food product preservation, their protection from chemical and physical damage, minimization of losses and reduction of preserving agents used in products. Packaging also helps to protect a shape and texture of meat products, prevent the loss of aroma and odor and extend shelf life due to the long-term preservation of their freshness [10].

Therefore, formation of meat product safety directly depends on packaging material quality. Food contact packaging should not be a source of biological (or microbiological), chemical or physical hazards $[11,12,13]$.

At present, the production and use of polypropylene packaging is growing with increasing rates, which can be explained by low specific mass at relatively high density, chemical inertness, low brittleness, easiness in staining, high processability and replaceability. However, several disadvantages of this packaging type can be highlighted, such as:
- off-odor from packaging that is not peculiar to a product;

- aging caused by the action of air oxygen, aggressive media and sun sight (in other words, photoaging);

- possible migration of organic/chemical substances into a packed product.

According to a functional purpose, polypropylene packaging is classified into consumer, industrial and transport. Consumer packaging from polypropylene became most common in agriculture, and in particular, in the meat industry. Its main task is to protect meat products from deformations, damage, spilling, drying and other types of losses. A shape, design and capacity of such packaging are determined according to properties and configuration of packed products and a method for its production. Packaging can have a capacity from several kilograms to several tens of kilograms. Consumer polypropylene packaging can be tough and soft. The main methods of its production are injection molding, thermal and vacuum forming and pressing [14].

Polypropylene is a product of propylene polymerization; i. e., it is a synthetic polymer. Over the last years, polypropylene has been more often used in manufacturing packaging for meat products. It is driving back polystyrene due to its larger strength and chemical stability, as well as many kinds of polyethylene due to its toughness and glossiness.

Chemical stability of polypropylene resides in the fact that only highly concentrated strong oxidizers can exert a notable effect on it, namely, chlorosulfonic acid, fuming nitric acid, sulfuric acid and halogens. Polypropylene has high chemical stability to contacts with alkali, salt solutions, mineral and vegetable oils, as well as alcohol containing products.

Polypropylene is quite sensitive to action of oxygen, especially at high temperatures, due to the presence of tertiary carbon atoms. This explains it proneness to aging, which can occur very quickly compared to other polymers and can be accompanied by a sharp decrease in its mechanical properties. Therefore, low doses of low molecular weight additives (stabilizers) that protect it from destruction both in the process of processing and during its use are added to avoid aging.

To protect polypropylene from light aging, light stabilizers are used. Their action resides in filtration of ultraviolet irradiation and its transformation into heat energy. Antioxidants help to avoid thermal oxidative aging of polypropylene.

Polypropylene is also quite water-stable material. After long contact with water during six month, water absorption is less than $0.5 \%$ (at a room temperature).

Plastic masses serving as raw materials for production of a polypropylene tray practically never consist of a single polymer material. To impart different performance characteristics, many various additives are introduced such as plasticizing agents, filling agents, stabilizing agents, crosslinking agents, colorants, foaming agents, lubricat- 
ing agents and so on. Compositions of plastic masses with equal distribution of raw materials are produced by mixing. To impart specific shape and size to polypropylene particles, granulation is carried out followed by the plasticization process - heating and homogenization of produced granules. To facilitate the process of the following formation when making a tray, polypropylene is solved in different types of liquids [15].

A wide geometric variety of packaging for meat products is presented in the modern market. There are polypropylene films, bags, containers and trays with different shapes and designs. All packaging types take into consideration product peculiarities and properties in one way or another. As meat products are perishable, most manufacturers prefer to pack a finished product immediately after production before chilling. Moreover, packaging of wholepiece meat semi-finished products should attract attention of buyers. These goals can be achieved by using different technologies, materials and substances $[15,16]$.

One of the most important packaging types for meat semi-finished products is a polypropylene tray that performs a range of the above mentioned functions, which in combination with special methods for designing and processing often allows obtaining economically beneficial solutions that justify its leading position in the market of packaging materials. In this regard, many Russian and foreign manufacturers prefer to use this type of packaging. With that, trays can be hermetically sealed, filled with a special gas or vacuumized, which allows the significant extension of product shelf life due to a decrease in the microbial ability to multiply. As a gas environment, inert gases mixed in certain proportions are used, which composition always depends on a particular packed product.
Packaging materials in normal or predicted conditions of the use should not lead to a risk of meat product contamination with chemical components in amounts that can present a risk for consumer health; changes in the finished product composition and deterioration of their sensory characteristics are also unacceptable. This requirement is applicable to all materials that come into contact with a product through direct contact or as a result of air exchange between them.

Packaging materials mainly present hazard of meat product contamination due to migration of packaging chemical substances (Figure 2). It is a multi-factor process that depends on the nature of a product and contacting material, as well as storage conditions (contact duration, temperature, humidity, light access and so on). Undoubtedly, emergence of modern inexpensive materials with antiseptic properties in the market and their introduction into production of packaging enable extending product shelf life. However, in many cases, their components are a threat to consumer health per se. A strict control of incoming raw materials and conditions of technological operations is necessary to avoid contamination of packaging materials and, as a consequence, meat products with chemical substances and compounds [16].

A serious threat for safety of polypropylene packaging can present such contaminants as molds, residues of cleaning agents, disinfectants, lubricating agents, foreign substances that enter the packaging environment due to non-observance of personal hygiene by employees or violation of sanitary rules in production as well as chemical risks. An unintentional introduction of foreign substances into the composition of raw plastic masses or directly to finished packages is also possible [16].

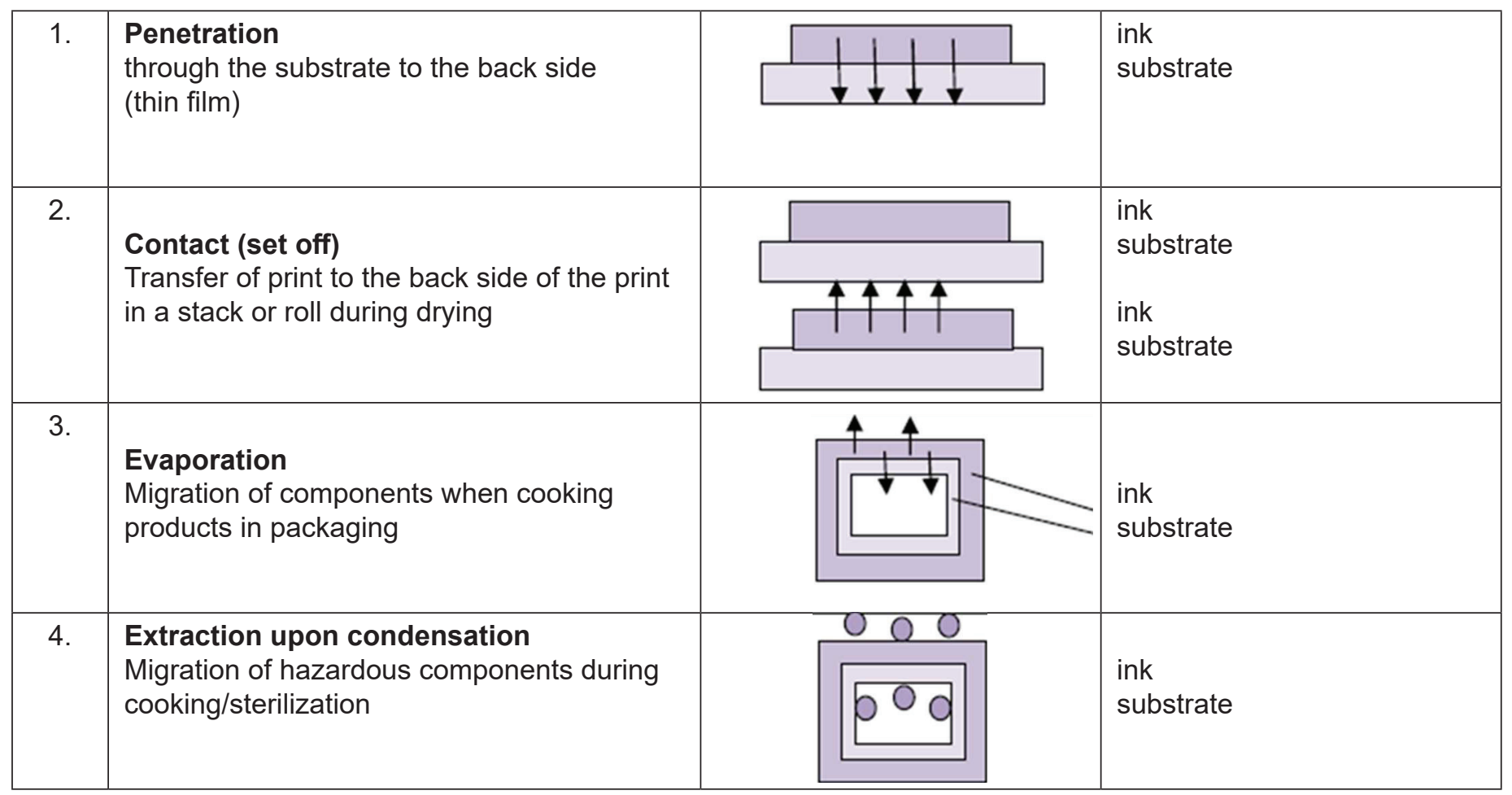

Figure 2. Migration of packaging chemical substances 
It is necessary to note that typical hazardous factors, measures for their prevention and correction and monitoring procedures regarding production of packaging materials for meat products are not established in Russia up to date. Therefore, based on the above stated, studies aimed towards developing elements of safety and quality management in their production are timely and topical.

\section{Materials and methods}

Taking into consideration the necessity of the effective risk analysis, in 2020, the Gorbatov Research Center for Food Systems carried out the research aimed towards developing elements of safety and quality management of packaging in a form of a tray, which is a final element of the united chain in production of whole-piece meat semi-finished products. The object of the research was packaging in a form of a tray from polypropylene as well as the system of management of hazardous factors in its production.

Within the framework of the studies carried out at the first stage of the work, the provisions of the HACCP system were realized, including:

- hazardous factors typical for production of polypropylene packaging were identified and described successively for each stage of the technological process;

- risk analysis was carried out - the probability of occurrence and realization of hazardous factors in the production process, as well as severity of consequences of their realization for an ultimate consumer were assessed;

- critical control points (CCPs) were revealed; for each CCP, the critical control limits were established;

- a Pareto chart was built to reveal the main causes influencing CCP realization;

- unacceptable risks were determined as well as operations and processes in production of polypropylene packaging where their appearance that leads to a negative effect on safety and quality of whole-piece meat semi-finished products is possible;

- preventive and corrective measures were developed with consideration for the established critical limits;

- requirements for CCP monitoring were established.

It is necessary to note that:

1. All studies of the production process were analyzed. First of all, the revealed risk assigned to the category of unacceptable risks (the zone of the high and medium risk) were taken into account.

2. If the same unacceptable risk could occur at several successive stages of the production process, the probability of its realization at later stages with regard to preventive actions on the preceding stages of the production process was analyzed (for example, regarding the microbial growth);

3. If the same unacceptable risk could occur at several successive stages of the production process and its realization at later stages in no way depended on control and preventive actions at the preceding stages of the production process, then the control was carried out at all indicated stages (for example, introduction of foreign substances).

To reveal critical control points, the method was used that envisaged the expert comparative assessment of the severity of consequences from realization of this factor and the probability of occurrence of this risk for each determined hazardous factor in production of a polypropylene tray for whole-piece meat semi-finished products using designations $[17,18]$.

\begin{tabular}{|l|c|l|}
\hline $\begin{array}{c}\text { Probability } \\
\text { of realization }\end{array}$ & Score & \multicolumn{1}{|c|}{ Severity of consequences } \\
\hline $\begin{array}{l}\text { Unlikely (for } \\
\text { example, once in } \\
\text { several years) }\end{array}$ & $\mathbf{1}$ & $\begin{array}{l}\text { Insignificant consequences (for } \\
\text { example, minor ailment that did } \\
\text { not lead to serious disorders in the } \\
\text { human body); }\end{array}$ \\
\hline $\begin{array}{l}\text { Very seldom (for } \\
\text { example, once a year) }\end{array}$ & 2 & $\begin{array}{l}\text { Consequences of medium severity } \\
\text { (for example, infliction of harm } \\
\text { that disappears over time without } \\
\text { hospitalization); }\end{array}$ \\
\hline $\begin{array}{l}\text { Seldom (for example, } \\
\text { once a month) }\end{array}$ & 3 & $\begin{array}{l}\text { Severe consequences (for example, } \\
\text { serious disorders in the human body } \\
\text { leading to hospitalization); }\end{array}$ \\
\hline $\begin{array}{l}\text { Quite often (for } \\
\text { example, every week, } \\
\text { every day) }\end{array}$ & $\mathbf{4}$ & $\begin{array}{l}\text { Critical consequences (for example, } \\
\text { serious deterioration of human } \\
\text { health that caused long-term } \\
\text { disability or death). }\end{array}$ \\
\hline
\end{tabular}

To detect CCT, it is necessary to calculate the aggregate coefficient, which was determined by the following way:

aggregate coefficient $=$ product of scores $/$ sum of scores

After all calculations, a scale for CCP determination from the min to max values (in this case from 0 to 1.5) was constructed (Figure 3).

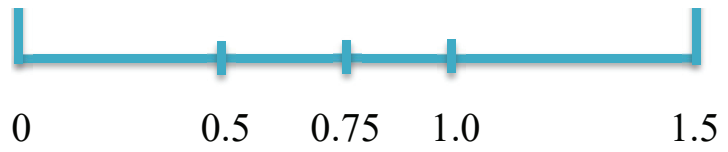

Figure 3. The scale for CCP determination from 0 to 0.75 - are not CCPs; from 0.76 to 1.1 - points that envisage the use of control to prevent a hazard but are not critical; from 1.2 and higher are CCPs.

\section{Results and discussion}

The first stage of activities towards developing elements of safety and quality management of polypropylene packaging for whole-piece meat semi-finished products was a construction of a production flow-chart. In this experimental work, packaging in a form of a tray was investigated. One of the widespread technological methods used in production of this type of packaging from polypropylene is injection molding.

In this method, initial polypropylene material in a form of granules or powder is loaded into a bin of a compression machine, where it is taken by the screw and is transported along the axis of the heated cylinder into its nozzle end being transformed from the solid to molten state. As the 
necessary volume of polymer melt is accumulated, it is injected due to the translational motion of the screw through the special nozzle to the closed injection mold, where chilling is performed. After the cavity of the form is filled, the polymer melt stays in it for some time under pressure and then is chilled. Then the injection mold is opened and a final product is removed from its cavity. After that, an excess of polypropylene is removed and the product edges are cut with special mechanisms.

The flow chart for production of polypropylene packaging used in the present study is presented in Figure 4.

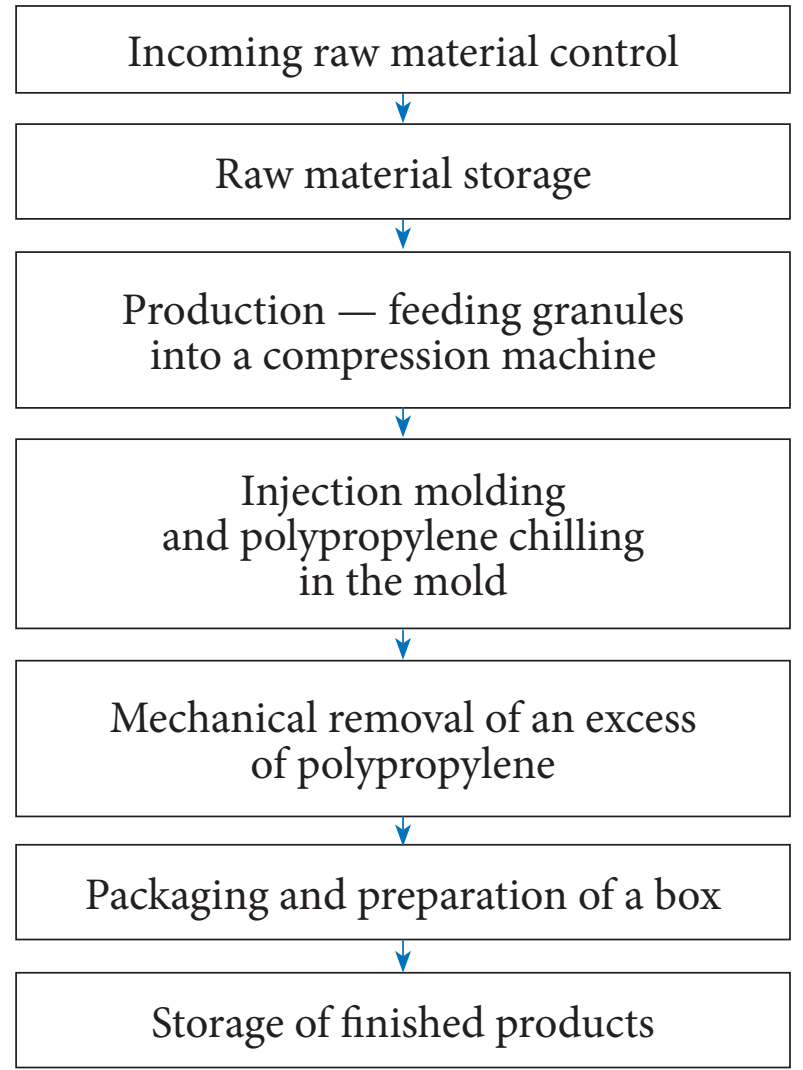

Figure 4. Flow chart for production of polypropylene packaging for whole- piece meat semi-finished products

The method of injection molding has several advantages compared to other methods of forming products from polypropylene. Among them are the high level of productivity, mechanization and automation of the realized process, a small amount of production waste and a possibility of setting practically any distribution of the product wall thickness.

After making a flow chart of production of packaging from polypropylene, potential hazardous factors (biological, chemical, physical), which can be realized at any technological stage, were identified. The result of determination that include their name, brief characteristics and assessment of the degree of their hazard for human life and health is presented in detail in Table 1.

It can be seen from this table that the serious threat for finished product safety can be posed by contaminants such as opportunistic microorganisms, molds, residues of cleaning agents and disinfectants, lubricating agents enter- ing the packaging environment due to non-compliance of personal hygiene by employees or violation of sanitary rules in production. An unintentional introduction of foreign objects into the composition of plastic masses or directly final packaging is also possible. With that, it is worth noting that polypropylene packaging being an object of the investigation in the present study poses a hazard directly by migration of plasticizing agents, heat stabilizers (epoxidized vegetable oils), lubricating agents, light stabilizers, antioxidants, solvents (carbohydrates, alcohols, glycol ethers, ketones and esters), as well as other chemical compounds [16].

When analyzing chemical hazardous factors, it is also necessary to consider procedures of internal control as emerging risks can be minimized due to the use of permitted and nontoxic cleaning agents for disinfection with corresponding supporting documentation (certificates of correspondence, declarations, instructions). It is also important to note appropriate training of cleaning personnel, control of disinfection procedures, effectiveness of cleaning of equipment, utensils and containers [13].

After identification of hazardous factors, the experts performed the risk analysis, which results are presented in Table 2.

As a result of analysis of risks influencing safety and quality of finished products, it was found that the main cause of the possible realization of a biological hazardous factor is non-observance of the established temperature and humidity conditions in warehouses for storage of raw materials and finished products. Absence or insufficient use of bactericidal lamps in the production zone, which work duration should be strictly regulated in the recording documents, also leads to an increase in undesirable microorganisms.

Personnel of an enterprise, in turn, also influence an appearance of the biological risk due to non-observance of rules of personal and production hygiene. Therefore, when developing and introducing preventive measures, manufacturers of packaging should plan timely training of each employee taking part in a technological process, including by the development of work instructions on the rules of personal hygiene, cleaning and disinfection of equipment, containers and utensils, as well as requirements for visitors of an enterprise and corresponding briefing.

During analysis of appearance of the physical risk, it was established that the most significant causes are personnel (the presence of foreign objects, non-observance of deratization and disinsection measures) and equipment failure (penetration of details and pieces).

Based on the revealed values, the expert group detected CCPs by using the scale presented in Figure 2.

Therefore, the stage "injection molding and chilling of polypropylene in a mold" was classified as a critical control point. As was described above, the process of polypropylene packaging production for meat products envisages introduction of acetaldehyde, formaldehyde, ethyl acetate, 
Table 1. Identification of hazardous factors for production of polypropylene tray

\begin{tabular}{|c|c|c|}
\hline \multicolumn{3}{|c|}{ Biological hazardous factors } \\
\hline Name & Brief characteristics & Degree of hazard. Severity of consequences \\
\hline $\begin{array}{l}\text { QMAFAnM, } \\
\text { CFU/g }\end{array}$ & $\begin{array}{l}\text { QMAFAnM includes different taxonomic groups of micro- } \\
\text { organisms - bacteria, yeasts, molds. } \\
\text { Exceeding indicates non-observance of the sanitary-hygienic } \\
\text { regimes. }\end{array}$ & $\begin{array}{l}\text { Foodborne Toxicoinfections. } \\
\text { Severity of consequences - low/medium. } \\
\text { Inflammatory process in the gastrointestinal tract after eating } \\
\text { food products containing living microorganisms in large quan- } \\
\text { tity (not less than } 107-108 \text { in } 1 \mathrm{~g} \text { ). }\end{array}$ \\
\hline $\begin{array}{l}\text { Coliforms, } \\
\text { E. coli }\end{array}$ & $\begin{array}{l}\text { Indicator microorganisms } \\
\text { Assigned to opportunistic microorganisms } \\
\text { Their presence indicates non-observance of the sanitary-hygien- } \\
\text { ic regimes. } \\
\text { Their presence in the finished products indicate the initial high } \\
\text { contamination of raw materials. }\end{array}$ & $\begin{array}{l}\text { Foodborne toxicoinfections. } \\
\text { Severity of consequences - low/medium. } \\
\text { Inflammatory process in the gastrointestinal tract after inges- } \\
\text { tion of enteropathogenic strains. }\end{array}$ \\
\hline Molds & $\begin{array}{l}\text { Molds secrete more than } 400 \text { different mycotoxins, all of which } \\
\text { are toxic for any individual. }\end{array}$ & $\begin{array}{l}\text { Severity of consequences - low/medium. } \\
\text { Mold colonies produce aflatoxins, which can accumulate in the } \\
\text { body and cause liver oncological diseases over time. Moreover, } \\
\text { molds can be a cause of diseases of the gastrointestinal tract of } \\
\text { different types and severity. }\end{array}$ \\
\hline Giardia cysts & $\begin{array}{l}\text { Giardia exists in two forms: motile (vegetative) and nonmotile } \\
\text { (cyst form). } \\
\text { Cysts are a nonmotile form of parasite life, which ensures sur- } \\
\text { vival of Giardia during long periods of time. At high humidity, } \\
\text { cysts survive for over } 2 \text { months. The spore form of the parasite is } \\
\text { tolerant to chlorine containing disinfectants. The motile form of } \\
\text { Giardia has four pairs of flagella and the adhesive disk, by which } \\
\text { it attaches to small intestinal mucosa. Infection occurs after } \\
\text { ingestion of food and water contaminated by Giardia cysts, as } \\
\text { well as through hands and surfaces contaminated by cysts. }\end{array}$ & $\begin{array}{l}\text { Giardiasis } \\
\text { Giardiasis is one of the most common parasitic diseases. } \\
\text { Giardiasis is dangerous both for adults and children. In terms } \\
\text { of human infection, a dose of about } 10-100 \text { is considered dan- } \\
\text { gerous. } \\
\text { Therefore, for disease onset and development, even minimal } \\
\text { contamination of the adult or child environment is sufficient. } \\
\text { If from one to } 10 \text { cysts enter the body, the risk of infection is } \\
\text { about } 10-30 \% \text {. } \\
\text { Severity of consequences: high }\end{array}$ \\
\hline
\end{tabular}

Formaldehyde $\begin{aligned} & \text { Formaldehyde has properties of an excellent antiseptic. There- } \\ & \text { fore, it is actively used in packaging production. }\end{aligned}$

Acetaldehyde Acetaldehyde is formed upon polypropylene thermal processing.

Severity of consequences - medium/ severe.

Formaldehyde can cause oncological diseases.

Severity of consequences - medium/ severe.

Depending on the concentration, symptoms range from slight irritation of the conjunctiva and upper respiratory tract to asphyxia, severe cough and stupor.

Ethyl acetate Ethyl acetate forms during production of the plastic mass upon reaction of acetic acid and ethanol.

Hexane, hexene, These organic compounds are used for polypropylene heptane, heptene production and preliminary processing.

\section{Acetone Organic substance used as a solvent in polypropylene production.}

Alcohols (methyl, Alcohols are used as solvents in polypropylene production. propyl, isopropyl, butyl, isobutyl)

Residues of cleaning agents and disinfectants, lubricating agents

Foreign objects from equipment

Foreign objects from personnel

\section{Polypropylene} residues

Pests (rodents, insects)

Dust chlorite, chloramine, sodium carbonate, liquid hand soap. ished products. pieces of electrical wires, pieces of the transporter belt).

Personal effects: buttons, earrings, jewelry, small objects, gloves.

Waste products from personnel - hair, fingernails. in their taste and deterioration of consumer properties.

Introduction of waste products from different pests into fintion facilities
Elements of cleaning agents and disinfectants: sodium hypoAbundant lubrication of the working surface of the equipment with oils can lead to contamination of raw materials and fin-

\section{Physical hazardous factors}

Small parts of the equipment (nuts, wood screws, bolts, screws, Severity of consequences - low/medium.

Introduction of polypropylene particles into final packaging for whole-piece meat semi-prepared products, which lead to changes

ished products due to the insufficient level of hygiene in produc-

It is a mechanical contaminant and a carrier of saprophytic microflora causative agent of spoilage, mold spores)
Severity of consequences - Mmedium/ severe.

Skin irritation; long inhalation can cause kidney and liver damage; it is toxic for the nervous system.

Severity of consequences - medium/ severe

Exert irritating action on skin; when ingested - lung damage; when inhaled, causes dizziness.

Severity of consequences - medium/severe Symptoms, such as abdominal pain, cyanosis, vomiting, nausea, can be observed

Severity of consequences - severe/critical

Appearance of severe headache, nausea, vomiting, disorder of the digestive system, intoxication of the whole body.

Severity of consequences - low/medium.

Depending on the chemical composition of a disinfectant: from mild intoxication to foodborne poisoning.

When ingesting small objects (less than 0.5-1 mm) that are not sharp - unpleasant sensations. When ingesting large objects or objects with sharp edges, it is possible to injure teeth, oral cavity, esophagus and stomach up to bleeding.

Severity of consequences - low/medium.

They can possibly cause physical traumas, as well as aesthetic aversion.

Severity of consequences - low/medium.

Severity of consequences - low/medium.

They can cause aesthetic aversion, as well as infectious diseases transmitted by pests.

Severity of consequences -low 


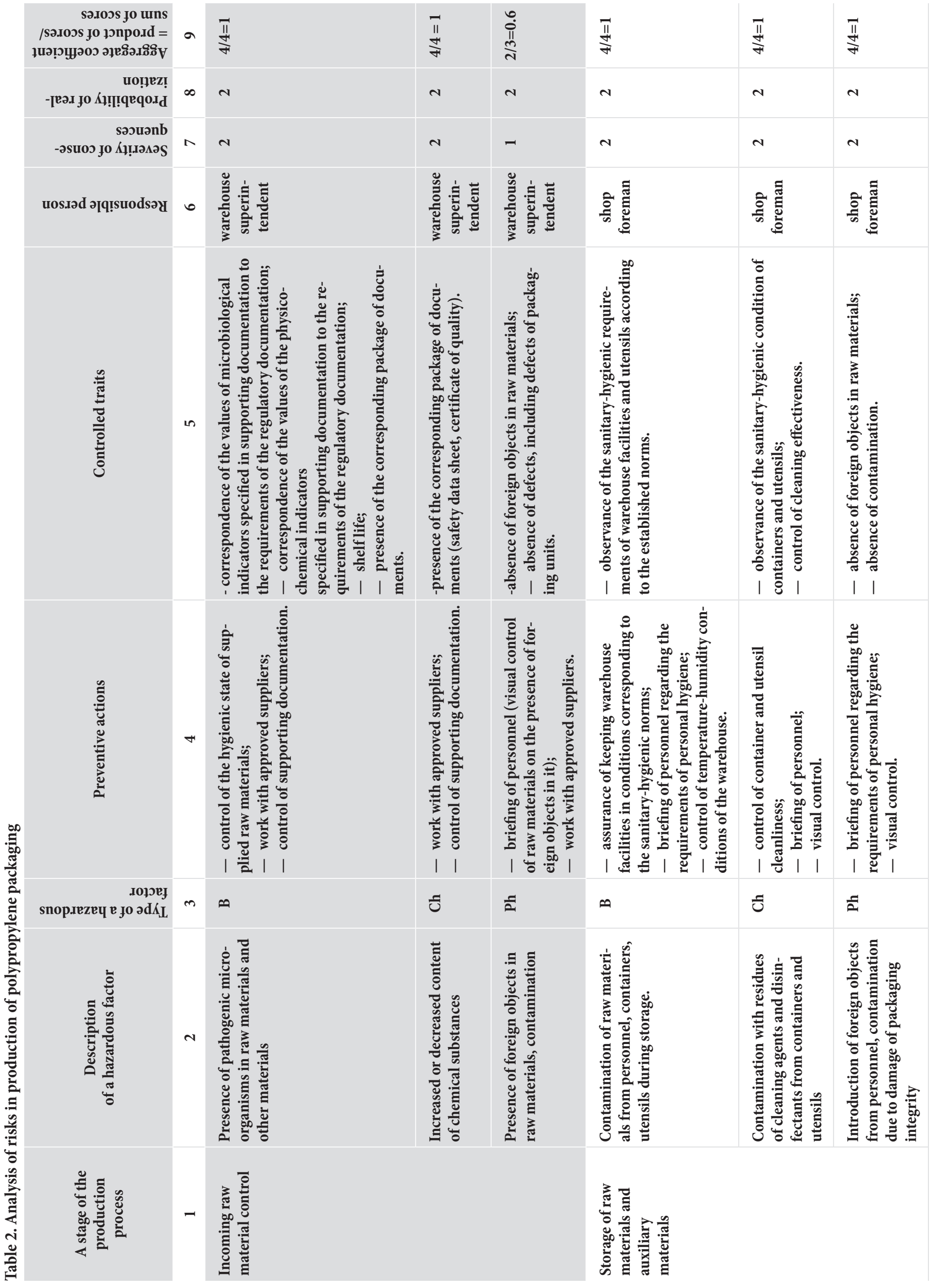




\begin{tabular}{|c|c|c|c|c|c|c|c|c|c|c|c|c|}
\hline 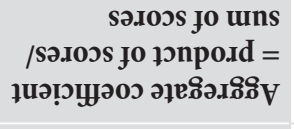 & a 1 & $1 \frac{\pi}{7}$ & $\frac{\pi}{2}$ & 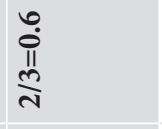 & I & $\frac{n}{2}$ & 11 & $1 \frac{\pi}{7 \pi}$ & $\frac{\pi}{7}$ & 1 & $\frac{\pi}{2 \pi}$ & 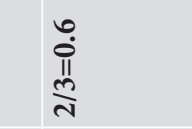 \\
\hline 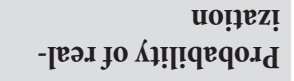 & $\infty 1$ & $\mid N$ & $N$ & - & I & m & 11 & $1 N$ & N & 1 & 12 & $1 N$ \\
\hline 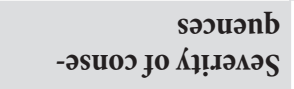 & -1 & $\mid N$ & N & N & I & m & 11 & 12 & $N$ & 1 & I N & $1-$ \\
\hline uos..əd ə|q!suodsəy & ○ & 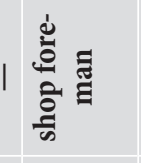 & 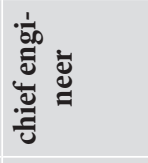 & 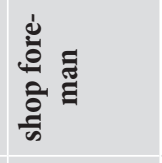 & 1 & 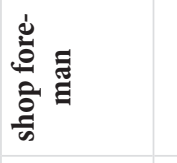 & 11 & 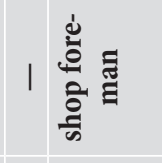 & 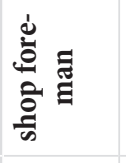 & । & 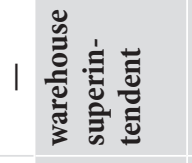 & 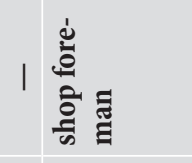 \\
\hline 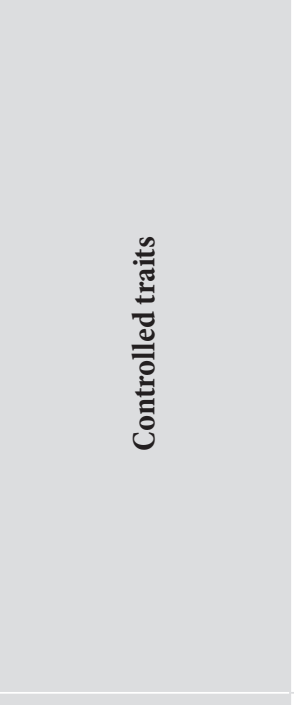 & in 1 & 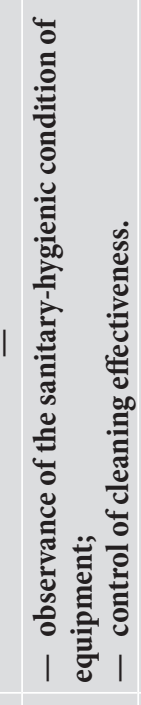 & 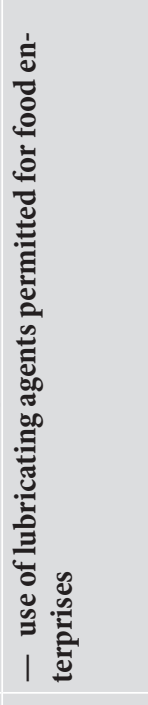 & 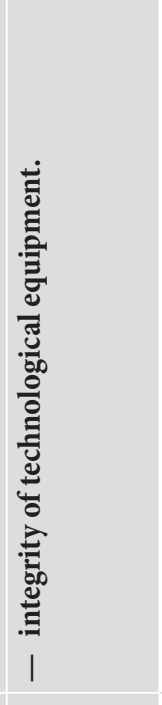 & I & 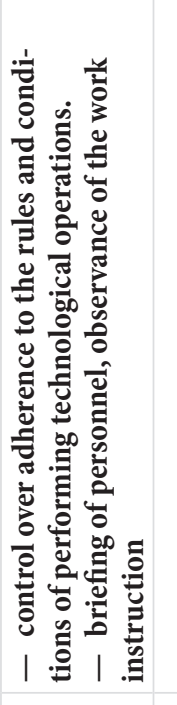 & $1 \quad 1$ & 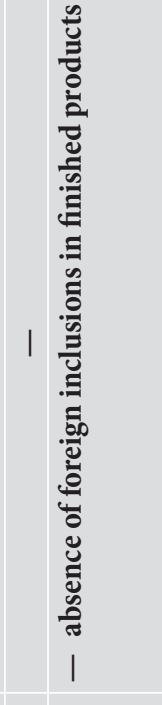 & 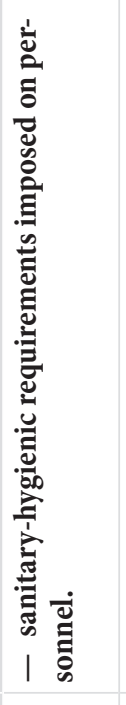 & I & 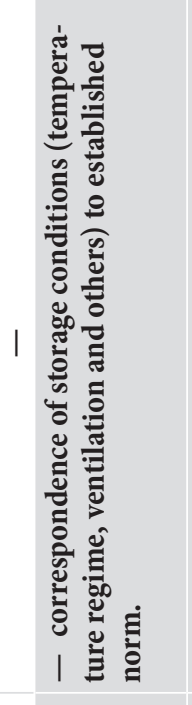 & 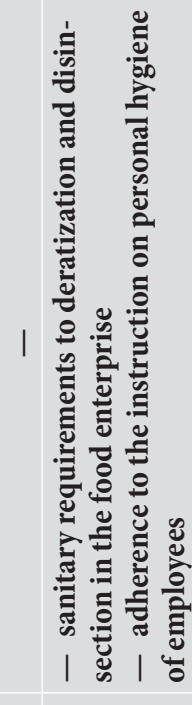 \\
\hline 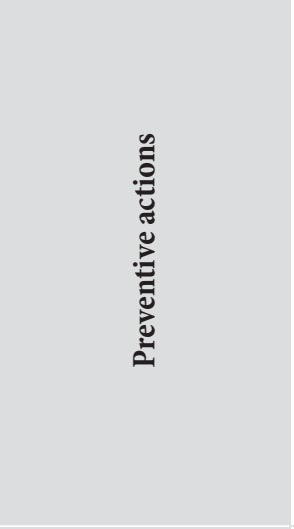 & H I & 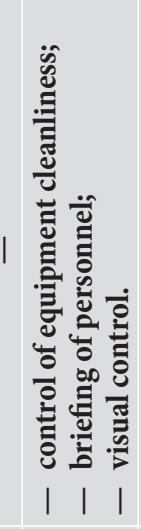 & 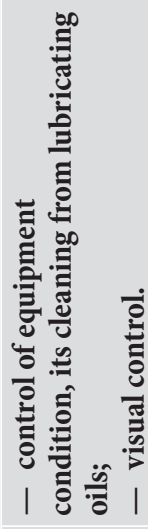 & 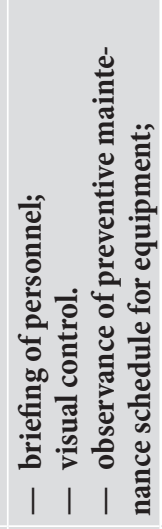 & & 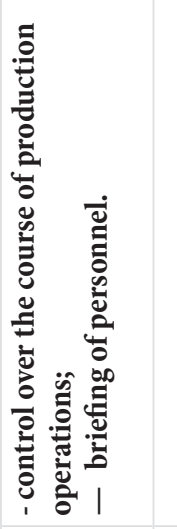 & 11 & 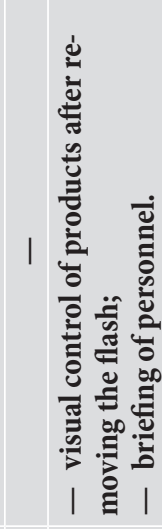 & 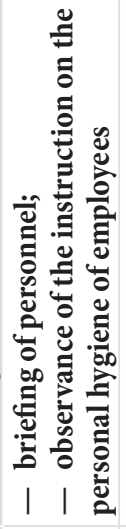 & 1 & 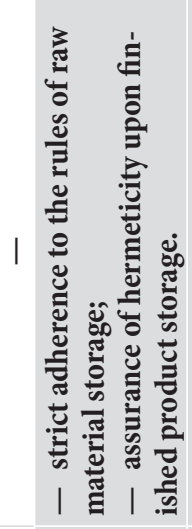 & 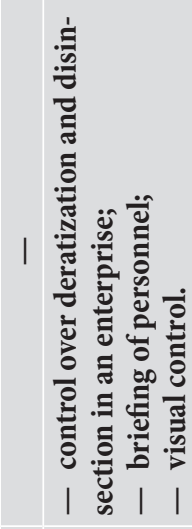 \\
\hline $\begin{array}{r}\text { лорэе } \\
\text { snop.вzzеч в јо әd }{ }_{\mathrm{L}}\end{array}$ & $m \infty$ & ๑ ฮี & తే & $\approx$ & $\infty$ & తే & 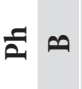 & ฮี ฐี & $\infty$ & ฮี & $\approx \approx$ & ปี జี \\
\hline 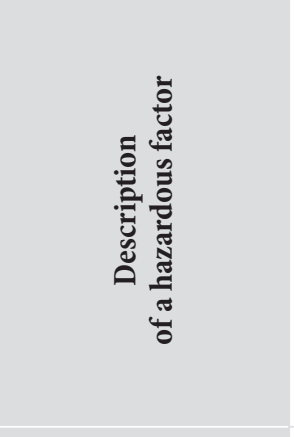 & 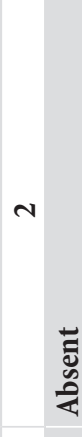 & 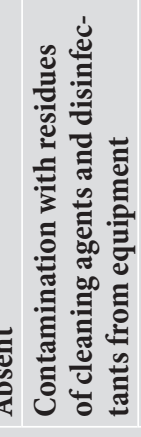 & 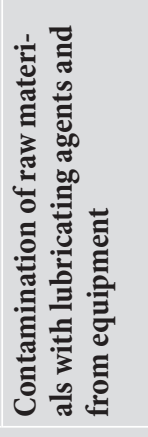 & 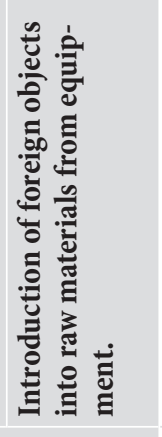 & 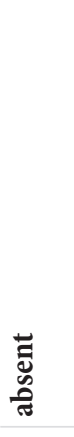 & 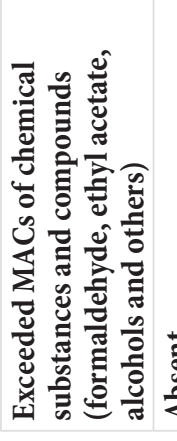 & 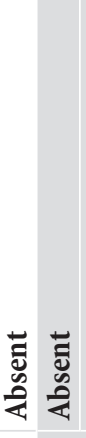 & 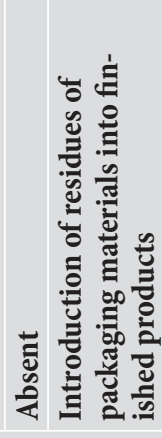 & 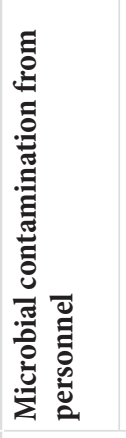 & 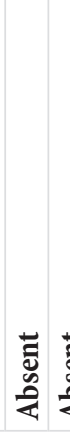 & 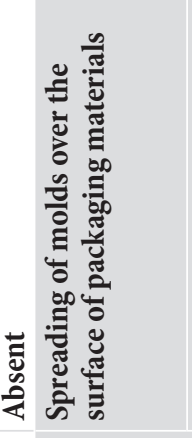 & 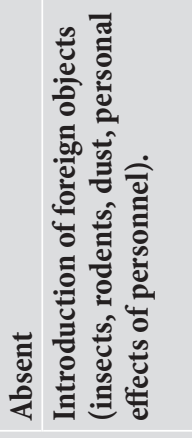 \\
\hline 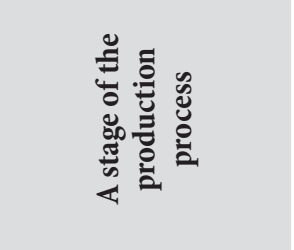 & 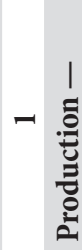 & 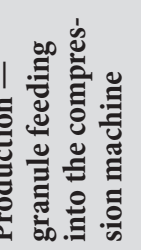 & & & 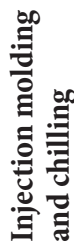 & & : & 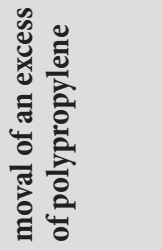 & 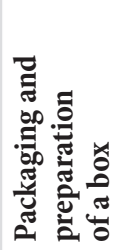 & & 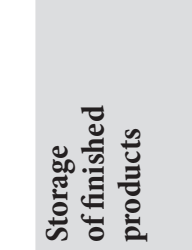 & \\
\hline
\end{tabular}


lubricating agents, light stabilizers, antioxidants, solvents (carbohydrates, alcohols, glycol ethers, ketones and esters), as well as other chemical compounds that can lead to the risk of chemical migration into food products [16]. In this connection, the excess of the level of hazardous chemical compounds and substances in a polypropylene tray is possible at this stage of its production, which later on can lead to appearance of the threat to safety and quality of packed whole-piece meat semi-finished products.

In the process of the detailed analysis, it is necessary to determine interrelationships of safety and quality indicators of both raw materials and finished products with all possible causes and to reveal an effect of causes at all stages of the technological process. Based on the analysis of risks and data obtained during the work, a Pareto chart was built (Figure 5), which allowed visual determination and assessment of the main causes influencing the CCP realization.
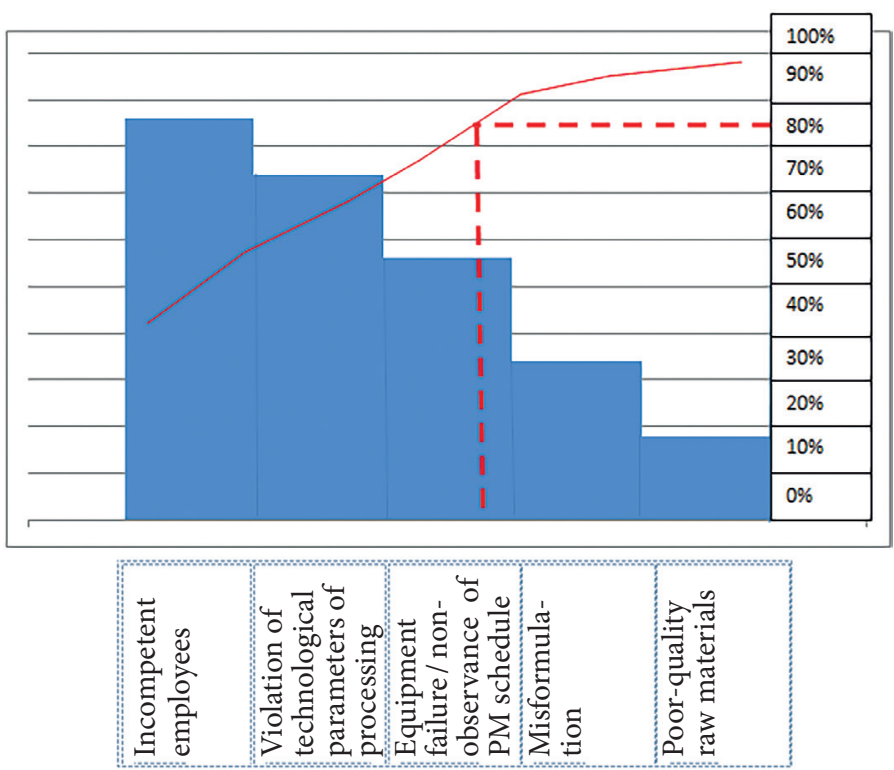

Figure 5. The Pareto chart for analysis of hazardous factors

The Pareto chart presents graphical interpretation of the so-called $80 / 20$ rule. These are causes sorted by a degree of importance, frequency of occurrence, costs, a level of indicators and so on. When ranking causes on the Pareto chart, the most important of them are arranged on the left side of the chart so that this vital minority can be easily identified. To increase informativeness of the Pareto chart, a cumulative frequency curve is usually plotted on it [17].

During the study of the Pareto chart, it was established that the realization of the chemical hazardous factor for the

Table 3. Critical limits, monitoring procedure and corrective actions

\begin{tabular}{|l|c|l|l|}
\multicolumn{1}{|c|}{ CCP } & $\begin{array}{c}\text { CCP } \\
\text { No. }\end{array}$ & \multicolumn{1}{|c|}{$\begin{array}{c}\text { Hazardous } \\
\text { factor }\end{array}$} & $\begin{array}{c}\text { Controlled parameter } \\
\text { and its limits }\end{array}$ \\
$\begin{array}{l}\text { Injection } \\
\text { molding and } \\
\text { chilling in a } \\
\text { press-mold }\end{array}$ & 1 & $\begin{array}{l}\text { Exceeded } \\
\text { MACs of chemical } \\
\text { substances and } \\
\text { compounds due to } \\
\text { equipment failure }\end{array}$ & $\begin{array}{l}\text { Acetaldehyde - } \mathbf{0 . 2 0 0 ~} \mathrm{mg} / \mathrm{l} . \\
\text { Presence of formaldehyde, } \\
\text { ethyl acetate, acetone, }\end{array}$ \\
$\begin{array}{l}\text { hexane, hexene, heptane, } \\
\text { heptene and alcohols is not } \\
\text { allowed }\end{array}$
\end{tabular}

identified CCP was influenced to a large extent by nonobservance of the preventive maintenance schedule for equipment (hereinafter, the PM schedule) and, as a consequence, possible equipment failure (80\%).

For minimization or prevention of this threat in production, therefore, it is necessary to introduce an effective monitoring system, which may include strict control of the PM schedule, maintenance support of equipment by competent personnel, briefing of personnel directly working at this technological stage as well as adherence to a given recipe and filling in established reporting documentation.

It is also worth noting that in case of using different dyes for printing on packaging, the content of hazardous substances in them that can migrate into meat products with favorable moist environment should be excluded.

At the last stage of the performed risk analysis, the monitoring procedure and corrective actions were determined. The developed measures on management of a critical control point are presented in Table 3 .

Therefore, by developing measures on prevention and correction of a hazardous factor in case of its realization and, subsequently, also a prerequisite program and introducing these measures into the production process of polypropylene film manufacture, it is possible, in principle, to exclude or significantly reduce the risk realization, which later on will ensure safety and quality of whole-piece meat products packed in this film.

\section{Conclusion}

Safety of packaging for meat products is achieved by interrelation of different indicators of materials used in its production, adherence to the sanitary-hygienic norms and absence of chemical contamination. With that, these requirements are used to all packaging types irrespective of the used material (natural, metal, polymer, carton, glass or combined materials).

The use of the results of the investigation allows organizing safety and quality control of manufactured produce (packaging), increasing its competitiveness, ensuring openness in relations with consumers and regulatory authorities. The hazard factor management, strict mechanism of preventive and corrective measures in production of polypropylene packaging give a manufacture confidence that safety and quality of manufactured products are maintained and controlled, which finally will lead to a decrease in the percent of nonconforming product outputs and, consequently, cost of quality.

Monitoring procedure

Daily control of the PM schedule. Remove produced plastic masses Monitoring of the record book for equipment maintenance on a shift basis.

Visual control of equipment integrity from production with entering a corresponding record into the check-list of the nonconforming products.

Call technical service to check equipment integrity 


\section{REFERENCES}

1. Kuzlyakina, Yu.A., Yurchak, Z.A., Kryuchenko, E.V. (2018) Analysis of the reasons for the implementation of a food safety management system in enterprises producing packaging for food products. Vsyo o myase, 6, 28-30. https://doi. org/10.21323/2071-2499-2018-6-28-30 (In Russian)

2. Liu, F., Rhim, H., Park, K., Xu, J., Lo, C.K.Y. (2021). HACCP certification in food industry: Trade-offs in product safety and firm performance. International Journal of Production Economics, 231 Article 107838. https://doi.org/10.1016/j.ijpe.2020.107838 3. Fotopoulos, C., Kafetzopoulos, D., Gotzamani, K. (2011) Critical factors for effective implementation of the HACCP system: a Pareto analysis. British Food Journal, 113(5), 578-597. https://doi.org/10.1108/00070701111131700

4. Zupanets, K., Bezugla, N., Tarasenko, O., Komarova, A. (2020). HACCP as a risk management tool for ensuring biosamples quality. Accreditation and Quality Assurance, 25(5-6), 383386. https://doi.org/10.1007/s00769-020-01448-2

5. Miarka, D., Urbańska, B., Kowalska, J. (2019). Traceability as a tool aiding food safety assurance on the example of a foodpacking plant. Accreditation and Quality Assurance, 24(3), 237244. https://doi.org/10.1007/s00769-018-01370-8

6. Kawecka, A. (2014). BRC/loP standard importance in packaging quality assurance. Production Engineering Archives, 3(4), 14-17. https://doi.org/10.30657/pea.2014.04.04

7. Lelieveld, H. L. M., Mostert, M. A., Holah, J. (2014). Handbook of hygiene control in the food industry. Woodhead Publishing. $-645 \mathrm{p}$. 8. Plank, C.M., Trela, B.C. (2018). A review of plastics use in winemaking: HACCP considerations. American Journal of Enology and Viticulture, 69(4), 307-320. https://doi.org/10.5344/ ajev.2018.17041

9. Bovee, E.H.G., De Kruijf, N., Jetten, J., Barendsz, A.W. (1997) HACCP approach to ensure the safety and quality of food packaging. Food Additives and Contaminants, 14(6-7), 721-735. https://doi.org/10.1080/02652039709374583

10. Ewart, M. (2012). Hazard and risk management in packaging. Book Chapter: Packaging Technology: Funda- mentals, Materials and Processes, 538-559. https://doi. org/10.1533/9780857095701

11. Sjöberg, A.-M., Sillanpää, J., Sipiläinen-Malm, T., Weber, A., Raaska, L. (2002). An implementation of the HACCP system in the production of food-packaging material. Journal of Industria Microbiology and Biotechnology, 28(4), 213-218. https://doi. org/10.1038/sj.jim.7000233

12. Chernukha, I.M., Khvorova, Yu.A. (2012). Control of hazardous factors at meat processing enterprises. Meat industry, 11, 12-15. (In Russian)

13. Kuzlyakina, Yu.A., Yurchak, Z.A. (2019). Hazardous factors in production of packages for meat products. Meat industry, 2, 38-41. (In Russian)

14. Su, Q.-Z., Lin, Q.-B., Chen, C.-F., Wu, Y.-M.a, Wu, L.-B. at al. (2015). Effect of antioxidants and light stabilisers on silver migration from nanosilver-polyethylene composite packaging films into food simulants. Food Additives and Contaminants - Part A Chemistry, Analysis, Control, Exposure and Risk Assessment, 32(9), 1561-1566. https://doi.org/ 10.1080/19440049.2015.1075258

15. Emblem, A., Emblem, H. (2012). Packaging technology. Fundamentals, materials and processes. Woodhead Publishing. $595 \mathrm{p}$.

16. Arvanitoyannis, I.S., Kotsanopoulos, K.V. (2014). Migration phenomenon in food packaging. Food-package interactions, mechanism, types of migrants, testing and relative legislation - A review. Food and Bioprocess Technology, 7(1), 21-36. https://doi.org/ 10.1007/s11947-013-1106-8

17. Kuzlyakina, Yu.A., Yurchak, Z.A., Kryuchenko, E.A., Kuznetsova, O.A. (2019). Risk analysis and identification of critical control points (CCP) in production of natural intestinal casings. The ory and practice of meat processing, 4(2), 4-13. https://doi. org/10.21323/2414-438X-2018-4-2-4-13

18. Pakbin, B., Kohannia, N. (2014, February). Risk management in food industries. 3rd International Conference on Behavioral Science At: Kish, Iran.

\section{AUTHOR INFORMATION}

Yulya A. Kuzlyakina - candidate of technical sciences, chief researcher, Department of technical regulation and food safety systems, V. M. Gorbatov Federal Research Center for Food Systems of Russian Academy of Sciences. 109316, Moscow, Talalikhina str., 26. Tel.: +7-495-676-35-29, E-mail: yu.kuzlyakina@fncps.ru

https://orcid.org/0000-0002-2152-620X

* corresponding author

Valentina S. Zamula - candidate of technical sciences, Department of technical regulation and food safety systems, V. M. Gorbatov Federal Research Center for Food Systems of Russian Academy of Sciences. 109316, Moscow, Talalikhina str., 26. Tel.: +7-495-676-35-29, E-mail: v.zamula@fncps.ru

https://orcid.org/0000-0003-1634-1486

Margarita V. Kochneva - candidate of technical sciences, Agroengineering Department, Peoples ' friendship University of Russia.117198, Moscow, Miklukho-Maklaya str., 8/2. Tel.: +7-495-434-70-07, E-mail: kochneva-mv@rudn.ru https://orcid.org/0000-0002-1442-4045

All authors bear responsibility for the work and presented data.

All authors made an equal contribution to the work.

The authors were equally involved in writing the manuscript and bear the equal responsibility for plagiarism.

The authors declare no conflict of interest.

Received 20.01.2021 Accepted in revised 09.03.2021 Accepted for publication 25.03.2021 